\title{
Measuring the urban private-public interface
}

\author{
A. van Nes \\ Section of Spatial Planning and Strategy, Faculty of Architecture, \\ Delft University of Technology, The Netherlands
}

\begin{abstract}
In contemporary urban policy making, the term "active frontages" of buildings is often used. However, a precise spatial definition in order to measure it is missing. As various studies have shown, the spatial configuration of a city's street and road net affects people's natural movement patterns and the distribution of shops and retail and the geographic and temporal distribution of crime and anti-social behaviour. However, the spatial relationships in these studies are mainly calculated on a macro spatial level.

Little research is done so far on the urban micro scale level when it comes to the spatial relationship between buildings and streets. The few conducted studies make it clear that a building's degree of exposure to neighbours plays a role on where burglaries take place. When revealing present design practice, the demand for privacy in combination with a demand for high quality dwellings in urban central areas seems to neglect the spatial possibilities for social interaction with their vicinity on an urban micro scale level. Up until now, spatial tools for measuring the topological relationship between private and public space were missing.

In a research project on space and crime, it became inevitable to pay attention to the interdependence between the macro as well as the micro scale spatial conditions. For this purpose, spatial analyses methods were developed and tested in the Dutch towns Alkmaar and Gouda. The application of these analyses tools shows clearly that micro scale spatial relationships have impact on street life and crime distribution in urban areas.
\end{abstract}

Keywords: spatial configuration, private-public interface, urban safety, street life, space syntax, micro scale tools. 


\section{The private - public space relationship and urban living}

During the last two decades, living in central urban areas has become popular in Europe. This kind of "urban renaissance" has contributed to an increase of estate and property prices in inner city areas. Several people seek for urban areas with high social, cultural and spatial diversity, short distances from dwellings to work, leisure and cultural activities, and to use all the opportunities a city has to offer [4].

Many recent urban renewal policy documents propose to intensify existing city and town centres instead of creating new out of town settlements. The idea is that high diversity and density of various kinds of land use, functions and cultural activities will contribute to vital lively urban areas and economic growth. As stated in most policy documents, the density of the built mass should be high without loosing good living qualities [5, p. 71] and [4, p. 45]. The compact city is used as a model for urban renewal for enhancing growth in existing centres instead of urban sprawl for promoting sustainable development. How this must be realised is, however, never demonstrated in recent policy documents.

What is striking is how project developers promote new housing areas in urban central areas. In their glossy brochures, full of pictures of traditional urban street life with a large variation of cafés and individual small shops and enterprises, they sell it as "urban living." Often the intention is to create lively and diverse urban areas. However, when it comes to the final product, the urban street life inside these areas is missing - even though the integration of the street net is high.

The topological spatial relationship between private and public space and its impact on urban life is a forgotten aspect in contemporary urban design and planning disciplines. Architects tend to emphasise the feeling of privacy within the context of modern living in their design projects. Often an explanation can be found in the individualisation process of human beings during the last 60 years in the western society. There seems to be a need for high degree of privacy when living together with others. However, when the city itself offers high degree of anonymity, then one can ask whether it is necessary or not hiding one's dwelling entrance and windows away from public streets. Urban project developers build with high density or a high floor-space-index and propose large variations of urban functions in new areas. However, the degree of inter-connectivity and the topological shallow public-private interface is often forgotten.

\section{Micro spatial relationships}

A method describing micro scale spatial variables in urban studies aims at defining the inter-relationship of buildings or private spaces and adjacent street segments. The focus is on how dwellings relate to the street network, the way buildings' entrances constitute streets, the degree of topological depth from private space to public space, and inter-visibility of doors and houses across streets. As Jane Jacobs and Jan Gehl argue, many entrances and windows facing a street is one formula to ensure urban liveliness [6] and [7]. The challenge is to quantify these kinds of spatial relationships. It is about measuring various degree of urban active frontages 
on the relationship between buildings and streets. Only then it will be possible to gain a genuine understanding on the spatial conditions for vital street life and urban safety.

\section{The method}

In a research project on space and crime in Alkmaar and Gouda, an opportunity was provided to register various spatial relationships between private and public spaces [8]. In each town one local area was chosen and studied in detail. These areas are more or less comparable when it comes to their function, size and the large variation of their social composition of dwellers and architectural composition in terms of a large mixture of various housing types. The local areas contain boroughs with homogeneous building types as well as areas with a mixture of several types. In total 1.168 street segments were observed and 25 different spatial features registered for each segment. The results of the micro spatial registrations were put in a database together with various macro scale variables derived from the space syntax analyses of the street and road net and the number and characteristics of residential burglaries and thefts from cars for each street segment.

There are several ways of analysing spatial configurative relationships between building entrances and the street network. An easily way is to register the topological depth between private and public space. This can be done as follows: one counts the number of semi-private and semi-public spaces one has to walk through to get from a private space to its public street. If an entrance is directly connected to a public street, it has no spaces between private and public space. Then the depth is equivalent to zero. If there is a small front garden between the entrance and the public street, the depth value is one since there is one space between the closed private space and the street. If the entrance is located on the side of the house and it has a front garden or it is covered behind hedges or fences then the topological depth of the entrance has a value of two. Entrances from back alleys covered behind a shed have a value of three. It is the topological steps between the street and the private spaces inside homes that are counted.

Entrances into flats can be represented in several ways. It all depends on the degree of permeability between the private space and the street. Some flats have upper walkways where the entrances to each apartment are connected, while others have a closed main entrance where visitors have to use a calling system. During registration the degree of permeability was used. Where a flat's front door or main entrance was permanently locked and provided with a doorbell or calling system, it was registered as a private space from thereon. When flats have open main entrances, the number of semi-private spaces was counted up to the apartments.

Each side of a street segment is registered separately. There are many streets where entrances are directly connected to the street on the one side, while there is a flat with an upper walk gallery on the other side. If a street segment's side has several depth values between private and public spaces, the average value is used. The diagram in figure 1 (top) illustrates various types of relationship between 

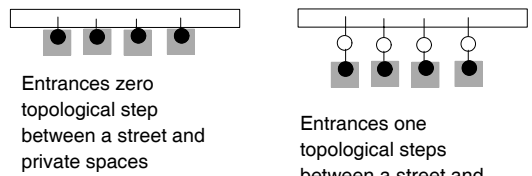

Entrances one

topological steps

between a street and

private spaces
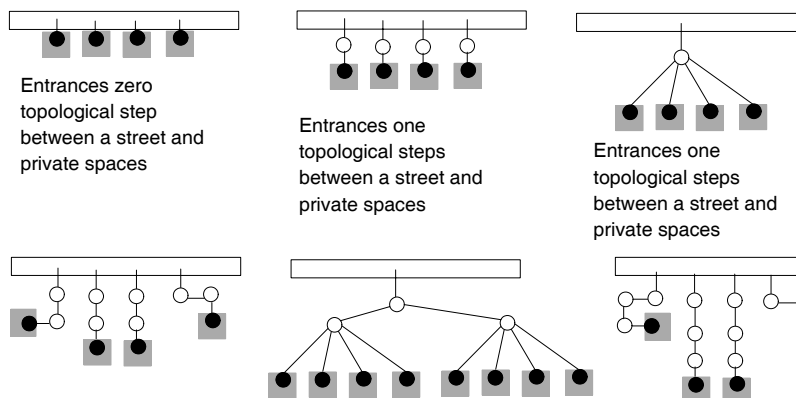

private spaces

Entrances two topological steps between a street and private spaces
Entrances two topological steps between a street and private spaces

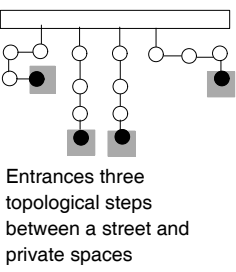

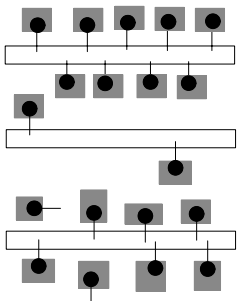

Examples on constituted streets
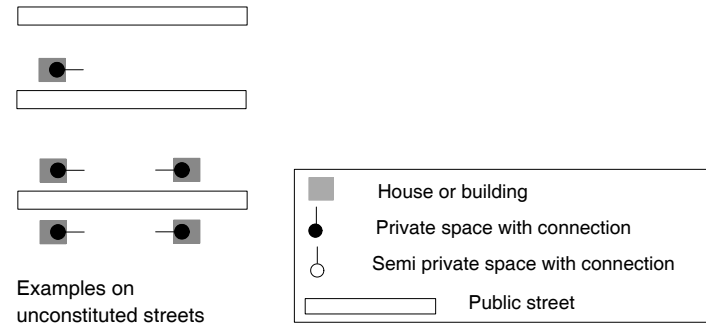

Figure 1: How the topological depth from entrances (top) and degree of constitutedness (below) is calculated.

private and public spaces. The black dots represent the private spaces, while the white dots represent semi-private spaces.

A street's degree of constitutedness depends on various degrees of adjacency and permeability from buildings to public space. When a building is directly accessible to a street, then it constitutes the street. Conversely, when all buildings are adjacent to a street, but the entrances are not directly accessible, then the street is un-constituted. A street segment is constituted when only one entrance is directly connected to the street. If the entrance is hidden behind high fences or hedges, or has a large front garden, or located on the side of the buildings, then the street is defined to be un-constituted. The diagram in figure 1 (below) illustrates the differences between constituted and un-constituted streets. The number and density of entrances are not at issue. The degree of constitutedness is about the number of entrances connected to a street divided by the number of buildings located along that street. 

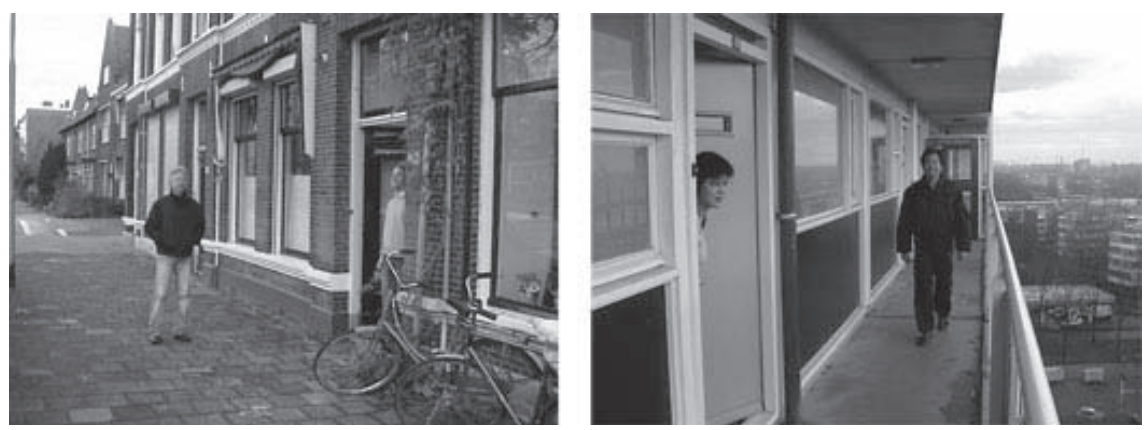

Figure 2: Example of a dwelling located to a traditional street (left) and a dwelling located on an upper walk-way in a flat (right). In the traditional street there is a direct connection between the private home and the public street. A stranger passing through one's front door is perceived as a source of safety. Conversely, in the case of the upper walk-way, there are many semi public and semi private spaces between the home and the street. A stranger passing through one's front door is perceived as a source of danger.

Figure 3 shows some examples on constituted and un-constituted streets. The two entrances on the top are constituted streets. In both cases the entrances are located only at one side of the street. The example on the left is a street dating from 1600 and the example on the right is a street from the 1970s. Both two streets below in figure 4 are un-constituted. No entrances are directly connected to these streets. The example on the left is a street located in a high rise flat area from the 1960s. One has to go into the semi public side streets in order to reach the flats' main entrances. Regards the example on the right, dating from the 1990s, all the apartments are located adjacent to the street. Even though the street is highly visible from all the apartments' windows, all entrances are located at the buildings' backsides and from the underground parking garages.

Figure 4 visualises the difference between constituted and un-constituted streets in Gouda. Un-constituted street segments are marked with a grey colour, while the constituted ones are in black. Most intruded homes (presented as dots) are entered from un-constituted street segments. The points of entry into dwellings are marked with a line from the street or back alley to the dot.

The more entrances connected to a street, the higher the probability that someone emerges from a private space into public space. However, high density of entrances connected to a street does not always imply high inter-visibility. There is a distinction in the way entrances constitute streets and in the way they are inter-visible to each other. The way entrances and windows are positioned to each other influences the probabilities for social control and street life. Figure 5 shows some diagrammatic principles on the relationship inter-visibility and density of entrances. 

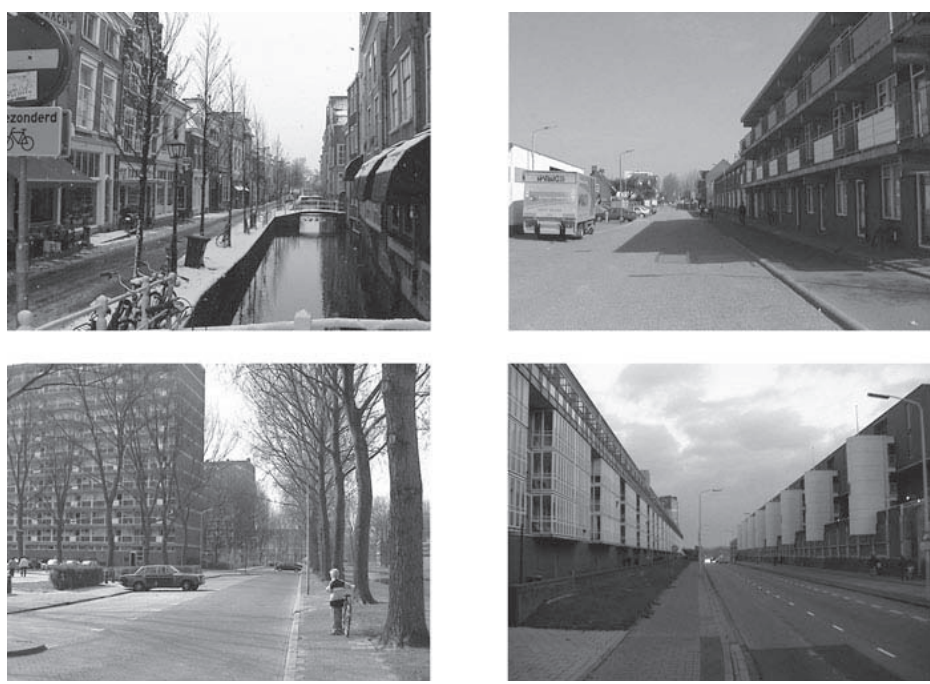

Figure 3: Example on constituted streets (above) and un-constituted streets (below).

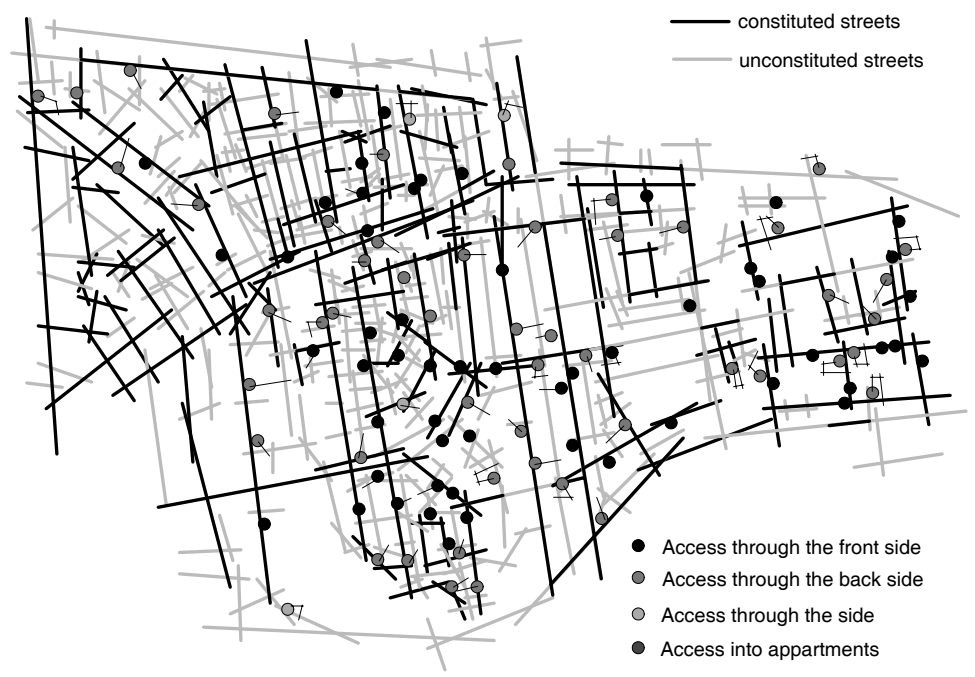

Figure 4: A visualisation of the constituted and un-constituted streets in Gouda.

In Alkmaar and Gouda the percentages were grouped in $100 \%, 80 \%, 60 \%, 40 \%$, $20 \%$ and $0 \%$ inter-visibility for each street segment. The density of houses and entrances was registered separately. Thus, two buildings with two entrances facing 

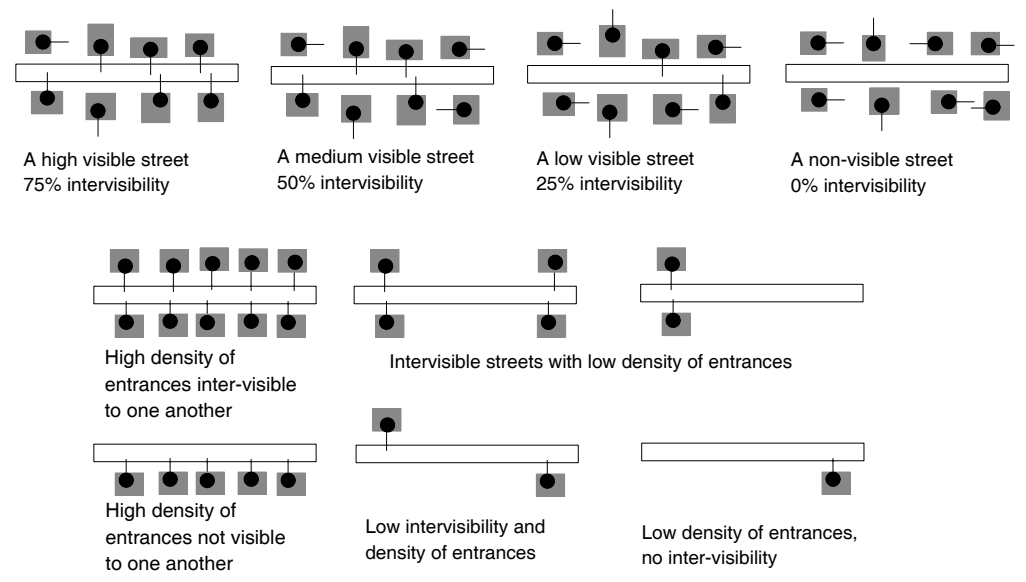

Figure 5: Diagrammatic principles on the relationship inter-visibility and density of entrances.

towards each other indicate $100 \%$ inter-visibility of doors. Conversely, a street segment with high density of entrances on only one side of the street segment and no entrances on the other side is defined to be $0 \%$ inter-visible. High density of entrances directly facing a street segment at only one side can be an indicator for street life, but is not necessarily a sufficient condition for crime prevention. A strong correlation was found between a street segment's inter-visibility and the risk on residential burglary [8].

The street form describes the mode of transport suitable for the street as well as the spatial possibilities for a perpetrator's escape. In line with Shu [3], street form was categorised as: through carriage ways, cul-de-sac carriage ways, pedestrianised street, cul-de-sac driveways, through footpaths, cul-de-sac front footpaths and cul-de-sac back alleys.

\section{Combinations of micro and macro spatial measurements}

A combination of various micro spatial measurements makes it possible to gain quantifiable spatial data for testing on socio-economic data and provide understanding on the spatial conditions for safe and vital urban areas. For example, a street with few connections to its vicinity (macro scale analyses) can still be full of social activities if a high density of entrances constitutes the street and when there is high visibility between public and private spaces (micro scale analyses). The reverse can be seen in un-constituted streets with a low number of entrances and low inter-visibility, but where the connections to other streets are high. Inde- 


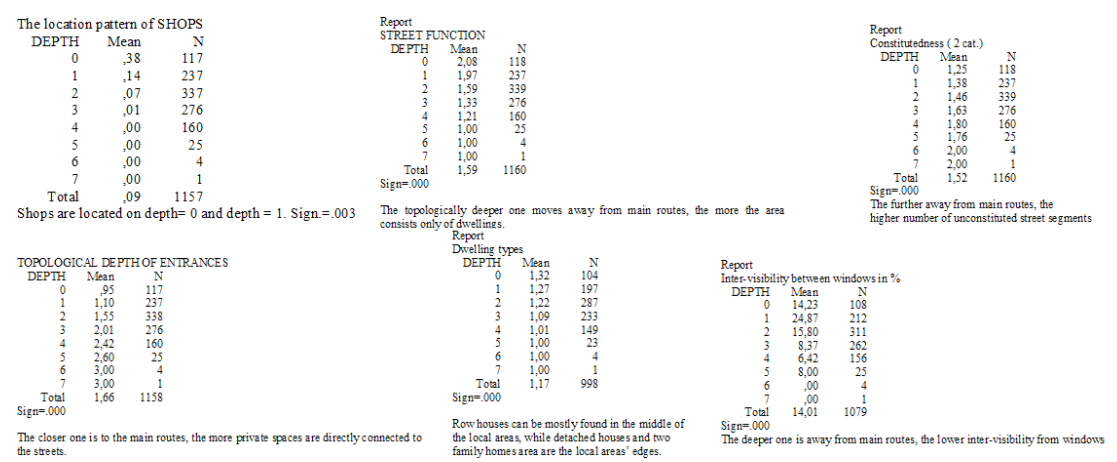

Figure 6: Statistical diagrams.

pendent of cultures and architectural styles, micro spatial measurements make it possible to describe the spatial set up of built environments on a local scale level.

As the results from the spatial analyses in Gouda and Alkmaar show, both micro and macro spatial variables are highly inter-dependent for describing areas' degree of liveliness [8]. Especially the topological depth of a street segment in relationship to its nearest main route gives a detailed description of the spatial set up of the area. Most micro spatial variables turn out to be related to the macro scale variable local angular analyses. This variable identifies the main routes through cities and shows strong correlations with the micro-scale variables. The following results were obtained (figure 6).

The further away a street segment is from the main routes net, the greater the topological depth between private and public space. Along the main routes through urban areas, most entrances are directly connected to the street. When changing direction two times from the main routes, the average topological depth for entrances is 2 while it is 3 in all street segments that are located more than six topological steps from the main routes.

Visitors usually frequent main routes, while only inhabitants frequent highly segregated streets in which gives neighbourhoods a desolated atmosphere. Dwellers inside these areas often prefer to protect their private life from insights from neighbours. When the streets are too much occupied by neighbours and there are almost no visitors around, the social control from neighbours can be too present. Therefore curtains and high hedges are used to prevent social control, and entrances are hidden away from streets and visible neighbours.

Urban areas located close or adjoining to main routes tend to have entrances directly connected to public streets. The streets are frequented by visitors as well as by inhabitants. The inhabitant wants to be a part of the urban street life. Often dwellers contribute to street life by sitting outside on a chair or the staircase in front of their homes. From their windows, dwellers keep an eye on what is going on outside. In many integrated areas, inhabitants like to contribute to the urban living by displaying their interiors to the view of passers by. 
The more segregated a street segment is, the more mono-functional the adjacent buildings tend to be. Topological deeply located street segment usually only have a residential function, since offices, shops and public buildings tend to locate themselves along the main routes. The semi-private segments are among the topological deepest and segregated streets. Row houses and flats tend to be located along topological shallow street segments, while maisonettes, vertical separated dwellings and detached and semi-detached houses are located at the areas edges.

The further a street segment is away from the main routes, the lower the values of spatial integration and constitutedness. Homes located along un-constituted streets deeply located inside urban areas with low inter-visibility from windows tend to have a high risk of being burglarised [8]. The un-constituted back alleys tend to be the most segregated street segments.

\section{The urban street plinth}

Micro spatial relationships play a crucial role in the socio-economic life of human beings. Often the concept "bringing back the human scale" is used in urban policy making. It refers to the metrical properties of space. Maybe a more genuine understanding on urban vital street life can be provided through a topological approach on urban micro scale level? In particular, urban renewal projects, modern housing areas and new large-scale urban development projects often tend to lack adjacency, permeability and inter-visibility between buildings and streets. This has negative effects both on street life and degree of safety of these areas.

High value on the floor-space-index is not always a condition for safe and lively streets. A "vertical city" like Hong Kong has several examples of new housing projects not well connected to the street. Even though the number of apartments is high, there is little street life at the street plinth [9]. Often stacking apartments can contribute to vertical sprawl, but it seems to depend on how these flats' entrances are connected to the street.

However, the degree of inter-connectivity and the topological shallow publicprivate interface is often forgotten. All these activities depend on how the spatial configuration is on the plinth or built up street sides. Therefore, there is a need to bring micro scale spatial relationships on the research, policy making as well as the design agenda in the urbanism discipline.

As the study of 1.168 street segments clearly shows, the micro spatial conditions of the street segment are inter-related to the macro spatial conditions of the cities' street network. The definition and operationalisation of the micro scale conditions is, however, still in a preliminary phase and an area that can be improved upon in the near future. At least, some concepts useful in urbanism are introduced and bring significant aspects into the urban sustainability and compact city debate. This is not only important for urban studies, but also for the design and planning of our cities. 


\section{Acknowledgements}

I want to thank Manuel López for his co-operation for the research project space and crime in Dutch built environments, the police offices from Alkmaar and Gouda for providing crime data, and the Politie \& Wetenschap for the research funding.

\section{References}

[1] Hillier, B., Penn, A., Hanson, J. et al., Natural movement: or, configuration and attraction in urban pedestrian movement. Environment and Planning B: Planning and Design, 20, pp. 29-66, 1996.

[2] Hillier, B. \& Sahbaz, O., High resolution analysis of crime patterns in urban street networks: an initial statistical sketch from an ongoing study of a london borough. Proceedings 5th International Space Syntax Symposium, ed. A. van Nes, Techne Press: Delft, pp. 451-479, 2005.

[3] Shu, C., Housing Layout and crime vulnerability. Ph.D. thesis, Bartlett School of Graduate Studies, University College London, London, 2000.

[4] Rogers, R., (ed.) Towards an Urban Renaissance, Urban Task Force. E \& FN Spon: New York, 1999.

[5] VROM, Ministerie van, Tussen woning en wijk. een straattypologie voor nederland. publicatienummer 01-04/VROM4008, Den Haag, 2004.

[6] Jacobs, J., The Death and Life of Great American Cities. Pimlico: London, 2000.

[7] Gehl, J., The life between buildings: using public space. Arkitektens Forlag: Copenhagen, 1996.

[8] López, M. \& van Nes, A., Space and crime in dutch built environments: Macro and micro scale spatial conditions for residential burglaries and thefts from cars. Proceedings 6th International Space Syntax Symposium, ed. A. Kubat, Istanbul Technical University: Istanbul, pp. 026.1-026.14, 2007.

[9] Hwang, I., When does stacking become vertical sprawl? The Sustainable City $I V$, eds. U. Mander, C. Brebbia \& E. Tiezzi, WIT Press: Wessex, pp. 283-292, 2006 . 